\title{
El grupo El Paso y la crítica de arte
}

\author{
José IGNACIO GÓMEZ ÁlvAREZ *
}

\begin{abstract}
RESUMEN ABSTRACT
El papel jugado por el grupo El Paso en los últimos años cincuenta y siguientes sigue siendo objeto de polémica. A través de la crítica de arte más representativa del momento y de la posterior y de las respectivas publicaciones dedicadas al grupo se estudia su alcance, las líneas que marcan la producción de sus integrantes y sus vías de ruptura con el panorama reinante.

The part played by the group EI Paso in the last fifties and following is still a matter of controversy. Through the most representative art criticism of the moment and subsequent and through the studies dedicated to the group its reach is studied, and also the outline that set up the production of their members and their ways of rupture with the prevailing scene.
\end{abstract}

Sigue aún abierta la polémica sobre la verdadera autoría de los cambios que tuvieron lugar en el arte de la España de los años cincuenta. $Y$ sobre si fue El Paso el catalizador de ellos o bien quienes ocupaban cargos institucionales. Eso sin contar las «gotas de audacia» de la Academia Breve de Crítica de Arte ${ }^{1}$ o los avances nada pacatos de Dau al Set, entre otros colectivos e individualidades que desde el intramuros español nos enseñaban qué era eso de las vanguardias a la altura de los tiempos.

* Licenciado en Historia del Arte. Universidad Complutense.

1 En el artículo 1.a de sus estatutos fijan su objetivo en «Orientar y difundir en España el arte moderno". Manuel Sánchez Camargo: Historia de la Academia Breve de Crítica de Arte. Biosca, Madrid, 1963, pág. 22. Eso ya era cantinela, por desatendida, desde los tiempos de la S.A.I. "Gotas de audacia" y no verdadero atrevimiento es lo que les atribuye F. Calvo Serraller: España. Medio siglo de arte de vanguardia (1939-1985). 2 vols. Fundación Santillana-Ministerio de Cultura, Madrid, 1985, pág. 92. 
Las respuestas no son taxativas ni sencillas y hay opiniones diversas para ello ${ }^{2:}$ las hay vehementes ${ }^{3}$ y las hay precavidas ${ }^{4}$. Sin duda alguna, no eran los integrantes de El Paso los únicos que creaban por entonces, ni mucho menos los únicos que lo hacían con una intención aperturista. Pero tuvieron su parte.

El mito de El Paso, ya consagrado en todos los círculos, se forja en las galerías y en las exposiciones internacionales como impone el sistema de difusión de las vanguardias. La necesidad del estudio del papel de las galerías ya ha sido reivindicado en repetidas ocasiones pese a que no se haya traducido en un aumento de la bibliografía ${ }^{5}$. Lo mismo puede decirse de las ex-

2 Valgan tres citas: «Los últimos cuarenta años del arte español han dado origen recientemente a no pocos montajes e interpretaciones fuertemente polémicos. Desde 1975 principalmente las publicaciones y exposiciones sobre este tema se suceden y en casi todos ellos, sea mayor o menor su calidad, abundan, como era lógico esperar, los trazos gruesos». F. CALVo SERRALLER: op.cit., pág. 14.

«Así pues, en conjunto, la I Bienal fue un éxito de hondísima trascendencia para el arte español contemporáneo, el cual (...) logró a partir de aquí la normalización de su panorama y dar comienzo a su sincronización con la escena artística internacional». Miguel CABAÑAS BRAvo: La política artística del franquismo. El hito de la Bienal Hispano-Americana de Arte. CSIC, Madrid, 1996, pág. 664.

«Todos hablan de El Paso y nadie se pone de acuerdo en cuestiones cruciales y, sobre todo, ninguno de los que tomaron parte en él». $M^{a}$ Santos GARCÍA FELGUERA: «Muchas dudas y algunas certezas. Reflexiones sobre el grupo El Paso», en Homenaje al Profesor Antonio Bonet Correa, 2 vols., UCM, 1994, pág. 1.553.

3 FERNÁNDEZ DEL AMO agradece que se rebatan por fin y en voz alta los sinfundios" de origen político que crearon la opinión de que fueron los de El Paso y no otros quienes pusieron a la España de Franco entre la pared y la espada del arte abstracto en una carta que publica $A$. ARóstegul: “El Paso», en su lugar histórico-artístico», en Correo del Arte, Madrid, n. 137, dic. 97ene. 98, pág. 4. La carta está fechada a 6 de julio de 1994. El Paso reconoció su deuda con Del Amo en Boletín n. 2, marzo 1957.

* V. BOzAL dice que «carecemos todavía de esa distancia histórica en la que el tiempo se encarga de limpiar y separar lo esencial de lo accesorio" al hablar de Tàpies, quien triunfa en esos años. Pintura y escultura españolas. 1939-1990. Summa Artis; vol. XXXVII. Espasa Calpe, Madrid, 1992. pág. 275. Aunque eso no exonera de realizar, por lo menos, las tareas propias del crítico, en ocasiones base de las del historiador.

s «Ha sido A.Bonet Correa quien ha insistido, en los últimos tiempos, en la necesidad de estudiar de modo suficiente la labor de las galerías (...) no sólo como instrumentos de comercialización sino también de difusión de los valores estéticos» A. MARTinez NoviLlo y J. TuselL: Cincuenta años de arte. Galería Biosca, 1940-1990. Turner, Madrid, 1991. pág. 23. Allí se reconoce que es tarea difícil en España por su escaso mercado, pasado azaroso y discontinuidad histórica. Como excepción mencionan a Juan A. Maragall: Historia de la Galería Parés. A. Bonet CorRea ponía de relieve esa ausencia en cat. exp. Juana Mordó. Por el arte. Círculo de Bellas Artes, Madrid, marzo 1985. pág. 76. Puede añadirse el artículo de FERNÁnDEZ POLANGo: «Las galerías de arte en el Madrid de postguerra", en Villa de Madrid, n. 97-98, marzo-abril 1988. págs. 5-27.

«Así, muy pronto, la iniciativa privada sustituyó a la pasividad oficial, que se demostró incapaz de proporcionar unos modelos positivos de gusto, y es a través de las galerías donde hay que seguir la evolución artística». Los años 40 son los de floración: Cano en Madrid (1940), Syra en Barcelona (1940), la ACBA en Biosca (1941), Estilo (1943), Buchholz (que inauguró la primera exposición de El Paso el 15 de abril de 1957) y Clan (1945), Galerías Layetanas (1948). F. CaLvo SerRAller: op. cit., p.86. 
posiciones nacionales e internacionales de arte ${ }^{6} . Y$ «en esta historia en curso de elaboración (...) empieza a ser igualmente importante fijarse en la letra pequeña, en el sordo rumor de lo cotidiano, en los perfiles más planos del horizonte" ", precisamente los cazaderos y el caldo de cultivo de la crítica.

De las exposiciones de los de El Paso en Fernando Fe, el Ateneo, Buchholz, Biosca y Juana Mordó, de las bienales de Alejandría, Sao Paulo y Venecia, se hicieron eco los críticos del momento dentro y fuera de España. Pero eso ya es reseñable: unos artistas que crean en España son destacados admirativamente fuera. González Robles figuró a la cabeza. Pero había algo más. ¿Qué dice la crítica? En ella nos centramos a continuación para conocer la aportación del grupo y las directrices que definen su papel dentro del arte español de los últimos años cincuenta y siguientes, aun cuando ya se hubieran disuelto. Esas líneas axiales que se discuten al socaire de El Paso son su inconformismo (político y artístico; real o aparente; estético y decorativo - dandi-o ético; por o contra el Estado), su posición entre la tradición y la modernidad (y la definición de las características del arte nacional), el problema del contenido en el informalismo, el origen de su gestualidad (francés, estadounidense, oriental, de tradición ibérica o de propia elaboración), si tienen o no teoría y si la quisieron tener, su carácter didáctico e instructivo de unas masas y aun élites que estaban ayunas del mínimo bagaje cultural en lo que concierne a las corrientes predominantes en el arte internacional. Algunas de estas cuestiones no son exclusivas de El Paso ni tampoco de esa década: la caracterización del arte español es una cuestión que suele remontarse a la generación del 98 y que vertebraría todas las obras creadas en el siglo presente ${ }^{8}$. El problema del contenido en el arte abstracto y la génesis de su vertiente gestual tampoco es exclusivo de la España de los cincuenta. Pero empecemos con los críticos y el desarrollo de los ejes mencionados. En primer lugar, no hay que olvidar que El Paso contaba con críticos en sus propias filas, algunos más por necesidad que por verdadera devoción ${ }^{\text {. }}$

- Vid. Fernando MARtín Martín sobre el pabellón de la exposición de París de 1937, los estudios sobre la ESAI, el de la 1 Bienal Hispano-Americana, y el libro de Me Dolores JIMÉNEZ-BLANCO: Arte y Estado en la España del siglo XX, Madid, Alianza, 1989.

Calvo Serraller: op. cit, pág. 15.

- Por ejemplo, Calvo Serraller al hilo del centenario de 1898 en Antiquaria, Madrid, enero 1998, o la justificación de F. Hulcl en cat. exp. Postrimerías. Representaciones de la muerte en el arte español contemporáneo, Fundación Mapfre. Vid. BOzAL y LLORENS: España, realidad artística y vanguardia social.

9 La marcha de Conde fue lo que les forzó a ello: "Ésta y no otra fue la razón que, con toda modestia, me indujo a asumir el papel circunstancial de escritor. Hecha excepción de Manolo Millares, la preparación literaria de los pintores de El Paso resultaba más que relativa. José Ayllón hizo lo que pudo y yo, por necesidad, me encargué del resto". S. AMón: "Conversación con A. 


\section{DEL LADO DE ACÁ}

Manuel Conde, poeta y encargado de las exposiciones de la galería Fernando $\mathrm{Fe}$, es miembro fundacional y será quien lleve el peso de las presentaciones del grupo ${ }^{10}$. Sin embargo, a los dos años justos, silenciosamente desaparece. Bozal, en su estudio de la crítica en los años sesenta no lo menciona, entendiéndose que por entonces carecía de peso como crítico en el panorama general ${ }^{11}$, pese a su valiente esfuerzo previo, si breve, por encontrar un lenguaje para la crítica ${ }^{12}$, y pese a que se le considere «el único teórico de cierta talla" dentro del grupo ${ }^{13}$. En cualquier caso, la imagen del grupo que Conde desarrolla puede considerarse, junto con la de Ayllón, como base del perfil que se quiere proyectar como grupo o conjunto de individualidades.

Su principal producción al respecto está contenida en artículos ${ }^{14}$. En ellos expuso el motivo principal de la aparición: "Apenas si existe un núcleo concreto de una conciencia colectiva coordinada para la realización de un arte más español y más universal, meta que será la propuesta fundamental del grupo "El Paso" ${ }^{15}$. Es decir, se parte poco menos que de la tabula rasa y todo está por hacer, cometido al que acude resuelto El Paso y objetivo que alcanza, según Conde, pues nadie más que los de la primera Escuela de Vallecas podrían hacerles sombra (junto con las aporta-

Saura sobre «El Paso»», El País, Madrid, 15 de enero de 1978. Saura había escrito en su juvenfud (Programio, 1951) y lo seguiria haciendo (Notebook (Memorias del tiempo), 1992). Millares participó en una revista literaria junto con sus hermanos antes de venir a Madrid en 1955. No todos ellos querían hablar, así Feito: "Prosigo mi camino, que no explico".

10 "Los artistas de «El Paso" exponen en Oviedo», Revista, Barcelona, 7-13 de septiembre de 1957.

"1 Bozal: op.cit., pág. 342. Todo ello pese a ser el «paladín» y encargado de presentar al Grupo Hondo.

${ }_{12}$ "El lenguaje de la crítica de arte y su eficacia», boletín n. 5-6, primavera 1958 y carta n. 2, marzo 1958.

${ }_{13}$ Laurence Toussaint: El Paso y el arte abstracto en España. Cátedra, Madrid, 1983. p.88. A la vez dice que el punto flaco del grupo es precisamente «el no tener «animador espiritual»», refiriéndose a un teórico.

${ }_{14}$ «Los artistas de «El Paso» exponen en Oviedo», loc. cit.; «Los pintores de El Paso», Cat. exp. Instituto Fernando el Católico, Pal. Provincial, Zaragoza, 21-ene a 4- feb 1958; «Una semana de arte abstracto", La moda en España, n. 223, Madrid, marzo 1958; "Pintura española de hoy», ibid., n. 227, julio de 1958; "La Bienal de Venecia», íbid., n. 228-229, ago-sept. 1958; "El lenguaje de la crítica de arte y su eficacia», loc. cit.; "Un punto de equilibrio para el arte actual», conferencia, Semana de Arte Abstracto organizada por El Paso, Sala Negra, 7-15 marzo 1958; «La peinture d'Antonio Saura", Aujourd'hui-Art et Architecture, n. 21, París, septiembre de 1959; «Panorama del arte español», Problemas del Arte Contemporáneo, n. 1, 1959; «Notas sobre el arte actual en España», B.A. 70, diciembre 1970; Cat.exp. Presencia de El Paso 30 años después, Junta de Castilla y León, s.l., s.f. (1987).

is "La peinture d'Antonio Saura", loc. cit. 
ciones de Buchholz y Clan) en su papel de revulsivos en medio de la situación penosa que vive el arte en España ${ }^{16}$.

Es de destacar el ingrediente de universalidad que intenta alcanzar El Paso para el arte español y el aislamiento con que se pinta a los artistas españoles del momento, incapaces de aglutinarse de una forma operativa, algo en lo que no alcanzó la trascendencia Dau al Set, seguramente por su descentramiento con respecto a la España de entonces. Sin embargo, este grupo - que interviene en sus publicaciones por la mano de Brossasí presta su modelo a El Paso, en la medida en que es el referente más cercano de colectivo organizado con críticos en sus filas, si bien Saura desde París ya conocía la mecánica. Sin embargo Conde insistirá años más tarde en la relación de El Paso con Dau al Set a través del carácter poético de ambos ${ }^{17}$.

Con respecto a la explicación de la cuestión de la gestualidad, Conde opina que diversos pueblos sin base común alguna pueden llegar a los mismos resultados estéticos. A esa poligénesis, sin embargo, se suma a posteriori la mutua influencia: Oriente influye pero es a su vez influido ${ }^{18}$. Son los años de la eclosión del Zen en el arte ${ }^{19}$, lo que motivaría los derroteros orientales que Conde toma: El Paso es tiempo y espacio en forma de signo y estructura. Pero si no parece sostenible inicialmente atribuir un origen oriental directo al abandono de la consciencia motriz en El Paso, más nos enfrentamos con ese origen si eliminamos el azar puro. Saura, pese a la admiración por Pollock, afirma que no le interesa "sumirse en una actividad pictórica sin control» ${ }^{20}$. Conde le retrata como «la caligrafía más expresiva de la pintura española actual» ${ }^{21}$ y para los

\footnotetext{
${ }^{16}$ «Estas afirmaciones (...) no son del todo exactas. Aunque hasta El Paso tal vez no hubo quienes tuvieran suficiente apoyo o fuerza para llevar adelante una labor de este tipo, si había, incluso en grupos, quienes se proponían objetivos mucho más actualizados que los de las escuelas madrileñas, de Madrid y de Vallecas". Julia Barroso: Grupos de pintura y grabado en España. 1939-1969, Universidad de Oviedo, 1979, pág. 43.

17 Cat. exp. Presencia de El Paso 30 años después, loc. cit.

18 "Los pintores de El Paso", loc.cit.

19 La codificación de esta corriente tan importante en general para la evolución del arte occidental, culmina en Obra abierta de Umberto ECO, en la que incluye su ensayo «EI Zen y Occidente", elaborado en 1959 y motivado por la «moda" que entonces se extendía desde los Estados Unidos. Allí relaciona esa influencia con la filosofía de Wittgenstein. El reconocimiento de Julius Bissier se realiza en esos años (1958), así como se conoce entonces en España a través de la exposición de Arte otro la trayectoria de Mark Tobey, instalado en un monasterio budista y primer premio de pintura en la Bienal de Venecia de 1958. Baumeister, también presente en España a través de la Escuela de Altamira, es fundador del grupo ZEN 49.

${ }^{20}$ Citado en J.M. BONET: Museo de arte abstracto español, Fundación Juan March, Madrid, 1991. pág. 26.

${ }^{21}$ "Los artistas de «El Paso» exponen en Oviedo", loc. cit.
} 
restantes integrantes de El Paso las referencias son a artistas que mucho tienen que ver con la mezcla de un misticismo y/o el abandono del control motriz tales como Pollock, Still y Rothko. E incluso relaciona la pintura de Juana Francés con la "serenidad extremo oriental». Y culmina su análisis con una frase que le sirvió de título para una conferencia: «un punto de equilibrio entre las dos tendencias más características del arte abstracto actual: el «informalismo»... y el expresionismo extremo-oriental, que este grupo de artistas españoles ha incorporado en su obra particular» ${ }^{22}$.

Todos ellos, según Conde, renuncian a lo grato, fácil y decorativo, algo que no toda la crítica compartía. Trabazo, en la polémica bien desarrollada habida en la revista índice, decía que eran artistas «de un cierto buen gusto", a lo que sumaban «una cierta inquietud», pero sin admitir que haya un contenido, siquiera sea «vacío» a lo Zen. No era el único en ver sólo una acción inconformista sin más, una pose. Castro Arines, en su crítica a la primera salida pública de El Paso, le atribuye una "condición decorativa», si bien animada por un espíritu de inconformismo ${ }^{23}$. La sombra del dandismo pesaba sobre El Paso. Y quizá haya que buscar esa filiación con el dandismo en la gestualidad misma. El hecho de que un gesto - controlado aquí- tenga un interés premeditado por estar cargado de un significado que no va más allá del gesto mismo ¿no remite directamente a la esencia del dandi, a su «religión»? ${ }^{24}$; si bien un dandismo pasado por el tamiz de la angustia catártica de Pollock y de la reciedumbre castellana, que no cumple el requisito baudelairiano de ocultar el esfuerzo.

José Ayllón es el otro crítico que compone El Paso desde sus orígenes -y que no abandonará hasta su disolución-y el autor material del primer manifiesto. Su presencia en los textos es menor que la de Conde, aunque la labor que desarrolla entre bambalinas es especialmente eficiente y decisiva: lo confirmarían su continuada adhesión y el que se le atribuya, junto con Saura, la decisión de la disolución. De su mano, entre los boletines,

${ }^{22}$ "Un punto de equilibrio para el arte actual", en la Semana de Arte Abstracto que organizó El Paso en la Sala Negra. Se inició una tesis doctoral sobre la presencia del Zen en el arte español sin resultados cerrados.

${ }^{23}$ "Las exposiciones: Grupo «El Paso»", en Informaciones, Madrid, 27 de abril 1957.

24 «Esa seguridad en las maneras (...) que revelan la fuerza (...) la necesidad ardiente de hacerse una originalidad (...) pocos hombres están dotados de la capacidad de ver; son aún menos los que poseen el poder de expresar". Ch. BAUDELAIRE: El pintor de la vida moderna. COAAT, Murcia, 1995. Recuérdese la elegancia desenfadada propugnada por Dubuffet -inspirador del art autre con resultados nada elegantes-que no tiene mérito si da placer porque entonces no es arte. J. DUBUfFET: Escritos sobre arte, Barral, Barcelona, 1975, págs. 65 y 79. 
además del manifiesto de febrero, se encuentran dos textos ${ }^{25}$. Si sirven de muestra de su tarea, desde luego ésta era un poco alucinada. En el primero, el lanzamiento del primer satélite Sputnik, acontecimiento impactante con razón, justifica unas reflexiones muy animosas que relacionan lo sideral con la bondad y que presentan la tarea de El Paso como una contribución a la regeneración espiritual ${ }^{26}$, lo que nunca está de más. Así, esa tarea «didáctica» que se imponen desde el manifiesto como necesidad acuciante no se limita a la asimilación de corrientes foráneas y a la vez escapa del puro inconformismo decorativo. Cómo debería desarrollarse esta tarea es algo que cada uno de los artistas irá proponiendo desde la evolución de su obra a falta de un programa claro y establecido pues las encendidas proclamas de Ayllón no dejan de tener bastante de brindis al sol, un sol que es el de los poetas pero de los que han sido avisados por los científicos de su magnitud y se ponen protectores para cantarlo con su tecno-jerga.

Antonio Saura, indiscutible alma mater, fue quien tuvo la idea de crear el grupo con el propósito de "sentar las bases de un futuro arte español de carácter universal en el cual predominen ciertas características mantenidas como constantes en el arte ibérico de todos los tiempos» ${ }^{27}$. Se encargaba con protagonismo desde su casa, donde se reunía el grupo, de la publicación de los boletines. A él le llegaban las publicaciones que el boletín anunciaba, codiciadas por afán profesional por Millares, según Toussaint.

En sus textos, y en los de A. Toro, su seudónimo, seguimos la caracterización que hace del grupo: la preocupación por el espacio (de raíz oriental), la definición como informalistas de todos ellos una vez dentro del grupo, la acuñación de la idea de que antes de ellos no había un panorama coherente. Finalmente, allí se justifica la disolución.

Es de suponer que el «carácter universal», además de aludir a las glorias pretéritas de nuestro arte, devenidas universales, tiene que ver con la opinión de Pollock, que Saura recoge en los boletines, de que no existen escuelas nacionales de pintura, como no las hay de matemáticas. Es a Pollock

25 En los números 1 (abril del 57) y 12-13 (verano del 59) y sin título. Otras intervenciones destacadas: "Panorama del siglo $X X$ ", conferencia de la Semana de Arte Abstracto, 7-15 marzo 1958; "La peinture espagnole contemporaine á Madrid», Aujourd'hui-Art et Architecture, n. 24, París, diciembre 1959.

${ }_{26}$ «Otra moral (...) nueva moral» son expresiones de Ayllón que se unen a las del manifiesto de verano del 57, de Saura, que empieza así: "EL PASO es una "actividad" que pretende crear un nuevo estado del espíritu...", y sigue más adelante "Luchamos por un arte hacia la salvación de la individualidad...".

27 Boletín n. 2, marzo 1957. 
a quien más admira ese Saura, aunque años después no figure entre sus preferidos. De él extrae ideas vertebradoras del grupo y de su pintura: «el concepto oriental de la pintura como un ser viviente» ${ }^{28}$ y la preocupación por el concepto de espacio en la pintura ${ }^{29}$, que podría hacerse extensible a todo El Paso: un espacio dependiente de la gestualidad que justifique los tamaños, que se convierte en soporte de ese gesto y de nada más, aunque materializando en sí una concepción del mundo, del arte y del tiempo: «El cuadro queda estructurado en una continuidad espacio-tiempo a través de una dinámica estructura (...) unidad cosmogónica en constante expansión» ${ }^{30}$.

La insistencia más o menos velada sobre la aportación de El Paso a la difusión y consolidación de las nuevas formas creativas puede seguirse en los manifiestos. Es lo que justifica su aparición y la publicación del primero. En ellos citan a la crítica internacional para apoyar la afirmación por si sus obras no fueran suficientes. Tras manifestar repetidamente la «aguda crisis" del arte español - y de lo que le rodea-, tanto en el manifiesto de febrero del 57 como en el de verano de ese año, El Paso se preocupó por destruir todo aquello que estaba caduco para construir después su discurso. Esa es al menos la recapitulación que proclama la «Última comunicación». Y, según ella, lo consiguieron. Las nuevas bases del futuro arte español estaban asentadas gracias a ellos como demostraba la receptibilidad de la juventud, algo impensable antes de su irrupción ${ }^{31}$. Tal

${ }^{28}$ Boletín, n. 4, invierno 1958. Un resumen de la unión con la obra, síntesis de la actitud oriental y occidental, es el de John CAGE: «When you start working everybody is in your studio - the past, your friends, enemies, the art world, and above all your own ideas - all are there. But as you continue painting, they start leaving, one by one, and you are left completely alone. Then if you're lucky, even you leave». En Cat. exp. Ian McKeever, Londres, Barbican Arts Centre.

${ }_{29}$ Esta preocupación puede verse en los títulos de sus conferencias: «Espacio y gesto» y «Signo y espacio».

${ }_{30}$ Boletín n. 4, invierno 58. Dedicado íntegramente a Pollock, incluye un texto de Saura en el que estudia el tiempo del caos en un espacio sin límites, y dos extensas citas del americano. Esa preocupación por el espacio, llegada desde EEUU, fue escarnezida por T. WOLFE: La palabra pintada, Alfaguara, Madrid.

31 Las ventas eran incluso crecidas: "Estos días se clausura una exposición del grupo El Paso de Madrid que ha despertado gran interés y que incluso ha tenido un resultado de venta mejor de lo esperado, dada la actitud del público general hacia el arte de vanguardia si bien esto va cambiando". Carta de Cirlot a Chillida con motivo de la exposición en la sala Gaspar fechada el 24 de enero de 1959, en J.E. CIRLot: De la crítica de arte a la filosofía del arte. Quaderns Crema, Barcelona, 1997. pág. 76.

Sólo «ahora, (ahora, no hace tres o cuatro años)" es cuando España puede salir sin sonrojarse a los certámenes internacionales, en contra de la opinión de Camón Aznar, crítico en $\mathrm{ABC}$, que decía que no hubo nada relevante en 1957, salvo la Exposición Nacional de Bellas Artes. Antonio TORO, desde la Carta 2, marzo 1958, se encarga de recordarle todos los acontecimientos que llevan a ese "ahora sí y no antes". Las Exposiciones Nacionales de BBAA cumplieron en 1956 sus 100 años, celebrando una exposición con obra de 177 artistas, ninguno de ellos vivo. «Desde 1960 hasta 1968 (...) fueron cayendo, cada vez más, y terminaron - jafortunadamente terminaron 
fue el impacto (pese a no poder cumplir con el programa de actividades, que incluía un salón anual como el de los Once) que el país mostraba un aspecto renovado con un «arte vivo, actual y progresista» ${ }^{32}$. La crítica internacional daba fe de esta vitalidad inesperada en el país de Franco ${ }^{33}$. $Y$ ese pasmo no fue pasajero. Los nombres que eran conocidos en el exterior, aunque no aseguraban la permanecia de la valoración positiva de tal panorama artístico, abrieron camino, si no a otras generaciones de artistas, sí a los que en ella trabajaban, así como a sus críticos ${ }^{34}$.

En cuanto a su aportación al arte español, había que saber, además de cómo estaba éste en ese momento, sobre qué invariantres construía. Ese "arte vivo" contenía la tradición artística española. Sin embargo, no llegó a explicitarse en qué consistía ésta. Apenas unas vagas referencias al dramatismo, la expresividad y la sobriedad, alusiones a la veta brava..., todo lo que no peque de «italianizante» o «neofauve» (i.e., lo que no caiga en el relapso de la Escuela de Madrid) ${ }^{35}$. Sin embargo, es fuera de los boletines en los que encontramos en mayor medida esta comparación con momentos anteriores: Saura relaciona a Chirino a través de la técnica de la forja con las rejas de las catedrales, con las de Gaudi y con Julio González ${ }^{36}$; a Millares y al propio Saura se les relacionó con los pudrideros de Valdés Leal ${ }^{37}$, mientras que los colores de Feito se asimilaban a la tradición española: los rojos y negros ¿acaso no tenían claras connotaciones españolas? Esos colores remitían a la tradición goyesca, a Eugenio Lucas. Goya que es estímulo de todo el grupo que ve en el Perro semihundido una obra emblemática y que motiva series enteras. Pero también la historia española es motivo de revisión; así en la obra de Millares

ya!- envueltos en el ludibrio". B. PANTORBA: Historia y crítica de las Exposiciones Nacionales de Bellas Artes celebradas en España, Madrid, 1946, págs. 343 y 349.

${ }_{32}$ "Última comunicación" y A. SAURA: "La Lección de Sao Paulo", en Arte vivo, Valencia, dic de 57 .

33 «La más bella sorpresa de la bienal» (de Venecia, 1958) según la prensa internacional, en SAURA: Carta n.3, nov 58. Estaban también presentes Rothko, Tobey, Wols, Kandinsky, Armitage, Pevsner, los italianos, etc.

${ }_{34}$ AgulleRA Cerni, por su labor como crítico sobre todo desde índice, recibió el premio internacional de la crítica en la XXXIX Bienal de Venecia, lo que da cuenta, junto con la presidencia de Cirici de la AlCA, del nivel alcanzado por la crítica en los años subsiguientes a los de El Paso, que quizás en eso contribuyeron. Empero, Calvo Serralier, en su España. Medio siglo de arte de vanguardia, ataca con dureza a la crítica de los setenta que distraida aún con la abstracción, perdió la oportunidad de lanzar internacionalmente a la generación de Pérez Villalta.

${ }_{35}$ Antonio ToRo: «Certámenes internacionales», en Carta, n. 2, marzo 1958.

36 A. SAURA: «Un escultor», en Cat.exp. Chirino, Col. Mayor San Pablo, Madrid, feb 1958.

${ }_{37}$ Refiriéndose a la Brigite Bardot de Saura, dice Cirlot: "Nuevo Valdés Leal, el artista parece decirnos a qué se reduce toda la belieza y toda la perecedera gracia de un rostro, de un cuerpo, de un temple femenino". Cit. en J.M. BONET: op.cit. 
(entre el amor y el odio por ella) y sus series sobre Felipe II, al igual que harán Saura y Rivera (y después el Equipo Crónica). La mística española ha salido a relucir en numerosas críticas de El Paso, así en las de Feito o en las de Viola ${ }^{38}$. Y en la de Canogar, a través de las relaciones con otro «místico», el Greco.

Su éxito les condujo a la disolución. No tanto porque hubiera intereses ególatras o crematísticos enfrentados, sino porque había que resolver una cuestión: la de dejarse utilizar por el Régimen en su campaña de imagen al exterior o enfrentarse abiertamente a él, tal y como imponía la ideología incluso comunista de sus integrantes. De una forma u otra, estaban abocados a la disolución pese a las reticencias de Saura por disolver el grupo ${ }^{39}$.

Manolo Millares, crítico por las razones que aducía Saura, establecía unas premisas en sus escasos textos: "No creemos - hoy- en un arte metido en la prudencia (...) La armonía no va con nuestro tiempo" ${ }^{40}$. A esos breves textos hay que unir la comedia en un solo acto "para no ser representada» - no hacía falta, se desarrollaba a diario - «El arte otro o el tiempo perdido" incluida en el segundo boletín.

Su alter ego, Sancho Negro, también medió en la definición del grupo con un extenso artículo ${ }^{41}$. Lo más característico de las intervenciones de Millares son sus consideraciones sobre la comprensión de la obra... ipor parte del artista! A todas luces, esto estimulaba el escándalo, no voluntariamente, pero, y aún hoy, intentar defender la libertad de la obra incluso ante el artista mismo no era sino una justificación más bien torpe de la impostura, un atentado al Arte por parte de unos sinvergüenzas autodenominados artistas, algo que ni el surrealismo ni dadá pudieron cambiar. No bastarían las contundentes afirmaciones de Saura contra lo establecido (calificó al Museo del Prado de "burdel de lujo») ni las de otros artistas que en ese momento arremetían contra el museo, justo cuando el museo imaginario más extendido estaba y más lisiado dejaba al museo físico - con menor efecto o con otro distinto-, para conseguir difundir una forma de entender la obra más allá de la pura autoconsagración en un

38 «Es el fantasma del tenebrismo o, mejor dicho, del realismo español del siglo XVII», dice Moreno Galván de Viola, a quien considera el más místico de nuestros pintores, quien rindió homenaje a Rothko en 1959.

${ }_{39}$ Vid. Boletín n. 16, mayo de 1960: “Última comunicación». Los motivos que se dan para la disolución son discutidos. En una carta de Millares a Cirlot (29 de octubre de 1959) ya apunta aquél desavenencias en el grupo. También Saura comenta con Cirlot la extinción del grupo. Vid. CIRLOT: De la crítica..., op.cit.

40 Carta n. 3, noviembre de 1958.

41 Sancho NEGRO: «El grupo El Paso en su primer año», Diario de Las Palmas, 17 mayo de 1958. 
entorno edilicio adecuado. La defensa de la autonomía de la obra de arte indudablemente conecta con el informalismo y más concretamente con la gestualidad, pese a que a ninguno de ellos (todo caso Viola) pueda definirse como un action painter completamente desinhibido: subyace, ya sea a través de figuras reconocibles, de estructuras matrices de origen figurativo o de un descontrol nunca del todo permitido, todo caso escogido y fácilmente visible, un orden dentro de las obras de todos ellos.

\section{DE UNO Y OTRO LADO}

A través de los boletines sobre todo, colaboraron con el grupo autores que en ocasiones llegaron a figurar como integrantes de él, casos de Cirlot y Aguilera Cerni ${ }^{42}$.

J.E. Cirlot, investigador y poeta del informalismo, a través de sus embriagadoras publicaciones concluye que El Paso nace "por la necesidad de dar una coherencia a la labor aislada de los artistas situados en la extrema vanguardia, tanto en el aspecto estético como en el social» ${ }^{43} \mathrm{y}$ se refiere a Die Brücke al reparar en el nombre de ambos ${ }^{44}$. La intención que ve en El Paso es la de servir de ejemplo en Madrid para la esperanza y la comprensión, o aceptación al menos.

Desde los boletines analiza las distintas posibilidades de interpretación del informalismo, todas ellas subyugantes y que siguen siendo válidas hoy en día a la hora de interpretar la obra no sólo de El Paso sino también de otros, como el Gustavo Torner que microscopia el paisaje. Es interesante también poner en relación con las obras de EI Paso la idea que Cirlot desarrolla bajo la entrada «Texturas» en su texto más querido, el Diccionario de Símbolos, y que aplica al "denominado «simbolismo soterrado» de algunas obras de arte en las que se ha creído ver una infrafiguración determinada

42 En el manifiesto definitivo aparecen como firmantes. Vid. Papeles de Son Armadans, n. 37, abril 1959, pág. 31. Cirlot, en Cat. exp. Four spanish painters, Gal. Pierre Matisse, N. Y., marzoabril 1960, reproducía su texto publicado parcialmente en el «Aviso didáctico" de los Papeles y en el boletín n. 5-6 pero ahora incluyéndose: «Nuestro objetivo es...» donde en castellano decía «El grupo El Paso fue constituido por...".

${ }_{43}$ Los textos directamente relacionados con el paso de Cirlot son Boletín n. 5-6, primavera 1958, de donde procede la cita; «Exposición de 4 pintores del grupo El Paso», Boletín n. 9, dic-ene 1959; «Aviso didáctico», en Papeles..., loc.cit.; Revista, Barcelona, 20 de diciembre de 1958; así como artículos de los Papeles... como «La obra de Pablo Serrano», n. 45, diciembre 1959, o en el ya citado cat.exp. de la galería neoyorquina Pierre Matisse y en el texto «La luz en la pintura española», en VV.AA.: La pintura informalista en España a través de los críticos, Dirección General de Relaciones Culturales, s.l., s.f. (1961), págs. 31 y ss.

${ }^{44}$ Ibídem. No será el único en hacerla. También C. Areán. 
por los juegos de sombras y luces, por los movimientos de las pinceladas o por los diseños del fondo". Recordemos los paisajes infrafigurativos que suelen verse en Feito, la pincelada simbólica de Viola y otros o los diseños de fondos de Rivera.

Cirlot encuentra «necesario significar que, bajo las diferencias de estilo y de concepto, ha de advertirse una profunda unidad [con Barcelona] que no puede nacer sino del temple del alma hispánica». Esa relación con la tradición no sería pues exclusiva de El Paso, ni siquiera autóctona. Tampoco otras características asignadas a El Paso lo serían. El ascetismo, los signos, la negación del color, la experimentalidad, la serialidad y la restricción de la imagen les asimila con los pintores más representativos de Barcelona que contaba con una modernidad más continuada que la de Madrid, donde Gutiérrez Solana permanecía aislado. Cirlot, conocedor perfecto del mecanismo de Dau al Set, establece esas comparaciones con El Paso para demostrar su valor, si bien no su unicidad. Lo que no quita para que sean «las expresiones más puras y exaltadas de la pintura hispánica actual».

V. Aguilera Cerni proponía frente a o abogando por un arte otro, un "arte además» de grandes horizontes y abiertamente definido ${ }^{45}$. El grupo, entre tanta crítica a la crítica, aventada desde sus manifiestos, le honró considerándole como «uno de los críticos de arte más responsables de nuestros días» ${ }^{46}$. Junto con Galván, Cirici y Cirlot, es destacado por Bozal en el panorama de la crítica de los sesenta ${ }^{47}$.

C.J. Cela no destaca en principio por su labor crítica, pese a sus múltiples textos que glosan obra de artistas ${ }^{48}$. Pero como director de Papeles de Son Armadans, que dedicó uno de sus números a El Paso en una fecha temprana y en unos años en los que la escisión entre los literatos y los artistas no se había completado, le hace figurar como personaje importante en la crítica del momento y en la difusión de El Paso. Y, sobre todo, porque es el que mejor aclara la ausencia de voluntad teórico-estética del grupo. Así abría aquel número: «El Paso no es grupo sustentado,

${ }_{45}$ Boletín n. 5-6, primavera 1958. Reproducido en Cat.exp. Presencia de El Paso 30 años después, op. cit.

46 Boletín n. 4, loc. cit.

47 «El desarrollo de la critica», Summa Artis, loc. cit., pág. 342 . Desde 1958 lideraba el heterogéneo Parpalló.

${ }_{48}$ De entre ellos extraemos una frase en la que no asoma una voluntad historiográfica: «Estremece pensar que un catálogo es algo muy parecido a un museo de figuras de cera o una sala de necesaria y dramática e inevitable disección. A todos los grandes creadores acaban disecándolos, iy peor para el que se pudre en el olvido sin haber despertado el interés de los rigurosos clasificadores de lo excepcional!". En Prólogo a Luis Mạ CARUNCHO, Luis Mosquera, Fundación Pedro Barrié de la Maza. A Coruña, 1992, p.9. 
a lo que colegimos, sobre bases o intenciones estéticas sino sobre postulados o puntos de partida éticos, morales y sociales". Más que una teoría, un código. Un código que va a hacer que el grupo sea «la última voz considerable aparecida en el tablado de las artes plásticas españolas ${ }^{49}$ ».

M. Tapié era el gran teórico del art autre que tanto impacto tuvo en el arte occidental justo cuando más parecía alejarse del corsé que significaba esa conscripción territorial. Y el mismo impacto tuvo sobre el arte de los españoles, ya estuvieran afincados en Francia o en España (así Tàpies y Saura, que figuraban en las listas de su galería: la Stadler; así Cuixart y Cirlot, glosador en España de la nueva etiqueta). Con ese arte otro, Tapié pretendía arrancar a la abstracción del huero decorativismo y aun del efecto emocional, vía psicosensorial, de las composiciones abstractas ${ }^{50}$ : "Ya no se puede hablar de artes de adorno, estética incluida, tan extremada, tan violentada como pueda ser: el arte se ejerce en otro lugar, en otro plano de esta Realidad que percibimos de otra manera, el arte es otro...». Según Tapié, su inspiración para tales lucubraciones le vino de Dubuffet, quien no definió su concepto de art brut porque el concepto mata la idea, porque la perfección termina con los valores de la ingenuidad (lo que el clasicismo llamaba amateurismo). Lejos de cualquier discurso intelectual que alejaría la producción del lenguaje comprensible para cualquiera, Dubuffet aboga por un arte que no se abandona al azar, sino que lo elige y consiente, que nace de espaldas al resultado y donde el pensamiento toma cuerpo. Es en ese contexto en el que cobra valor el gesto y la materia de los que hay que partir: «El arte ha de nacer de la materia. Importa más el modo de aplicar el color que el color mismo» ${ }^{51}$. Tanto materia como azar elegido son características de EI Paso.

J. Brossa debe ser incluido en este recuento siquiera sea de forma testimonial: con alguno de sus textos participó en los boletines.

\section{DEL LADO DE ALLÁ}

Entre los críticos que en mayor medida tuvieron un papel en la difusión del grupo o en la formación de su imagen mientras ésta estaba en desa-

\footnotetext{
49 “Señoras y señores», Papeles.., loc.cit., págs. 3.y 8.

50 Las de Kandinsky y las que analizó R.Arheim tras la Gestalt. Tapié dio un texto a El Paso que salió en el boletín número 10 (feb del 59) titulado «Note sur la communication» y que abordaba el problema del contenido en las nuevas obras de arte. Se apoyaba en paradigmas matemáticos, descubriendo un lenguaje que hay que conocer y que tiene otras necesidades no directamente explicitables.

51 J. DUBUfFET: op.cit.
} 
rrollo o aún ni existía figura Trabazo, que desde Índice polemiza con Saura y Ayllón, de lo que da cuenta uno de sus boletines y a lo que ya hemos aludido. Como también figura D'Ors, santón indiscutible del momento pese a lo controvertido de sus presupuestos ideológicos, que acogió en sus salones a Saura y a Millares. Se empeñaba en defender que el arte nuevo era ya popular. Si ciertamente contribuyó a ello, fue pese al elitismo del punto de partida de la ACBA. El secretario de ella, Sánchez Camargo, tuvo la gallardía de alabarles con motivo de la exposición Arte otro, en la que demostraron estar a la altura, o superar incluso, a los artistas más renombrados internacionalmente, mediante la búsqueda en su fuero interno de la sensibilidad, el conocimiento o el proceso mental que interese a los demás.

Lafuente Ferrari, siempre con un excepcional y ejemplar sentido del oficio de historiador y la docencia, participó con algunos textos sobre los integrantes de EI Paso ${ }^{52}$. Lo mismo que Popovici, cosmopolita a fuer de su vagar, cuya labor en pro del arte de los españoles fue importante para su conocimiento fuera de nuestras fronteras, y quien básicamente veía en la pintura informal española una tragedia desprendida de su materia, una materia que equivale al arte, un arte que por ello es español, unamunianamente español, una españolidad que se ve en la materia sacada de los paisajes castellanos ${ }^{53}$. Pero una tragedia que no agota la obra sino que la deja abierta y no consumida, que tiene que ver con la necesidad vehemente de "violar» la tela de la que habla Saura y con la «fiera intencionalidad de reforma» del arte verdadero a la que alude Cela.

Y lo propio con J.J. Tharrats, otro nexo con Dau al Set, que desde el semanario Revista publicaba su sección «Artistas de hoy» ${ }^{54}$. Lo mismo que desde Barcelona llegaba con motivo de la exposición de El Paso alli en enero de 1959 la afirmación rotunda de Teixidor: «desde los tiempos de Dau al Set no había aparecido en nuestro país un grupo artístico tan coherente que con méritos tan evidentes exigiera nuestra atención» ${ }^{55}$.

Fernández del Amo, además de su ingente labor al frente del Museo de Arte Moderno o Contemporáneo, contribuyó con alguna publicación ${ }^{56}$, ade-

\footnotetext{
52 "Pablo Serrano, escultor a dos vertientes", en Cuadernos de Arte del Ateneo, n.14, Madrid, 1957.

53 «La pintura española de los nuevos materiales», en VV.AA., op. cit., págs. 47 y ss. «Las arpilleras de Millares», en Cuadernos de Arte del Ateneo, n. 16, Madrid, 1957.

${ }^{54}$ Dedicada a M. Millares, n. 265, 18 mayo 57; a A. Saura, n. 280, 26 oct. 57; a R. Canogar, n. 294, 28 jun. 58 ; a L. Feito, n. 330,9 ago. 58.

55 Juan TEIXIDOR: «Los pintores de El Paso», en Destino, 17 enero 1959, p.23.

56 «Rafael Canogar», en Cuadernos de Arte del Ateneo, n. 20, Madrid, 1957.
} 
más de con su peso oficial. Como de González Robles cabe significar su ya sobradamente significada audacia a la hora de comisariar exposiciones y a la hora de montarlas ${ }^{57}$ en pro de un arte español nuevo que tiene un lenguaje informal pero que - destaca didácticamente González Robles-, cuenta con un serio pasado formalista pese a que ahora su lenguaje sea el de la pasta pictórica, el de la Materia, por la que el arte español tiene especial predilección no por moda sino por absoluta convicción ${ }^{58}$.

La crítica francesa fue especialmente receptiva a los ecos que del art autre llegaban de vuelta allí. Fue la primera en mostrar su asombro por los éxitos de los españoles. No en vano ya contaban en sus galerías con una buena representación de la mejor pintura española del momento y del grupo casi sin excepciones. Desde la revista Cimaise ya desde marzo-abril del 59 reseñan la obra española, como también lo hízo Cahiers du Musée de Poche. Tapié dirigía la Galería Stadler y en 1952 había publicado su Un Art Autre. De él, de su libro y de la exposición homónima se hace eco una de las cartas de El Paso. De la exposición de Saura en Stadler (octubre del 57), destacó las «violencias ascético-telúricas de Saura negro-plateado». Restany en Cimaise apoyó a Saura con motivo de esa exposición: indiscutible, fuera de serie junto con Tàpies, gesto sin moraleja, acuidad de sus grafismos. Choay, desde L'Oeil, en un artículo muy comentado, destacaba la pintura española como el acontecimiento más importante de la década ${ }^{59}$. Fue Choay quien exacerbó los tintes españolistas de la pintura del grupo en un acto de romanticismo indigestado ${ }^{60}$.

La crítica internacional les descubre en la Bienal de Sao Paulo de 1957. Allí y en Venecia al año siguiente El Paso consigue dar su do de pecho ante la crítica, y aunque el interés de ésta por un país tal pudiera ser pasajero, no lo sería ya para los componentes estables de El Paso aun en sus andaduras en solitario ${ }^{61}$.

${ }^{57}$ El mayor elogio lo encontramos en C. AREÁN: Veinte años de pintura de vanguardia española, Editora Nacional, Madrid, 1961. págs. 59 y ss.

${ }_{56}$ “El lenguaje de la pasta pictórica», en VV.AA., op.cit., págs. 43 y ss.

59 Todos los datos proceden de Laurence TOUSSAINT: op.cit.

60 Según Garcia Felguera en su texto citado, donde defiende la falta de españolismo en la pintura del grupo, ya que en su informalidad podía verse lo que se quisiera y "el cuento de lo español» resulta "poco claro y problemático», no mereciendo «tanto bombo" y antes debiendo buscar la raíz en Pollock, De Kooning, Kline, Appel, Burri y Vedova que en Goya y el Greco. Vedova, ¿undécimo miembro del grupo? se preguntaba J.M.Bonet quien incluye al Motherwell de las Elegías entre los antecedentes claros.

61 Uno de sus puntos de atención será la tradición, sobre todo a través de Feito. «A ojos de la crítica extranjera (...) Feito aparecía entonces como uno de nuestros vanguardistas que más entroncaban con una cierta tradición artística española. Una de las razones (...) radica en lo que sus cuadros de aquel entonces tenían de paisajístico». J.M. BONET: Museo de arte abstracto español. Fundación Juan March, Madrid, 1991. 


\section{DE OTROS LADOS}

Entre los críticos y historiadores que más peso han tenido a la hora de fijar las opiniones sobre El Paso están Areán y Moreno Galván, que si podían entrar en otros epígrafes (sobre todo Moreno Galván, íntimo conocedor de Millares) las fechas de publicación de sus obras, posteriores a la extinción del grupo, les remiten aquí.

Carlos Areán, apenas un año después de la disolución del grupo, publica su estudio Veinte años de pintura..., de tortuosas y entregadas sintaxis e imágenes, que fue un estudio influyente según el número de bibliografías en las que aparece, y destacable, además, por gestarse en el momento en el que la valoración de la influencia de El Paso nacía junto con su mito. Allí Feito es el artista del grupo más destacado, no sólo por su juventud sino también por haber logrado una de las siete síntesis de la «forma fluctuante». La precocidad también es un punto que destaca a Canogar, por lo que ambos ocupan un puesto en el estudio por encima de Saura y Millares, curiosamente.

Las referencias a los colores castellanos, a la tradición, son frecuentes; así como el paroxismo del enfrentamiento con el lienzo en un autodespedazarse, en una protesta y rebeldía que les lleva a la destrucción de sus lienzos (casos de Saura y Canogar). Con Cirlot se pregunta sobre Saura: "¿Conseguirá algún día dominar ese hervoroso universo que proyecta, y detenerlo en un éxtasis estático?" ${ }^{62}$. Es de destacar el carácter antidecorativo de la producción de estos artistas «ante los que es preciso suspender todo juicio estrictamente estético" y que se relaciona con su "sistemática destrucción de todas las viejas reglas de la estética clásica» ${ }^{63}$.

Pese a dar un fuerte protagonismo a González Robles y Fernández del Amo en su papel de promotores de cambios, fue El Paso el que logró «ejercer una palpable influencia sobre la opinión plástica nacional» ${ }^{64}$, sobresaliendo sobre el resto de grupos y actividades.

Moreno Galván, como buen marxista, sostenía que los cambios en los estilos son debidos no al azar sino a la sociedad, a la Historia. En el caso de El Paso ocurriría lo mismo: no contarían tanto las individualidades como el momento en el que se desarrollan ${ }^{65}$ : «Toda obra de arte recoge la

${ }_{62}$ Vid. pág. 89 de la obra mencionada. Ver también sus 30 años de arte español, Guadarrama Madrid, 1972.

63 Ibídem. págs. 89 y 182.

64 Ibídem, p. 57.

6s «Propósito» y pág. 137 en introducción a la pintura española actual. Publicaciones españolas, Madrid, 1960. 
realidad general de su tiempo y tiende a transformar el orden del mundo». Nada más lejos del puro decorativismo desde su interpretación materialista histórica, discutible, en este caso, porque eso no explica por qué El Paso, como conjunto de individualidades, no modificó sustantivamente su forma de expresión tras la muerte de Franco, si exceptuamos a Canogar. Todo caso sería válido si suponemos que El Paso no atacaba al franquismo sino a las vivencias que imponía, que podrían haberse continuado. Coincidiría así con Bozal en que eso tendría una base existencialista y cuando éste afirma que «la cultura, y el arte con ella, era antifranquismo» ${ }^{66}$.

Aboga por la tradición como modernidad, algo que desde las antípodas ya hizo D'Ors, sin que deba confundirse tradición con academicismo ${ }^{67}$. Sin embargo, analizando el informalismo (al que prefiere llamar aformalis$\mathrm{mo})$, piensa que tiene la virtud de haber abolido las fronteras entre el arte occidental y el del resto de mundo; occidentalocentrismo que se altera ante la presencia oriental y de las culturas «primitivas». Destaca la síntesis conseguida por el aformalismo al superponer arte y vida desde el momento en que el azar es una forma válida de creación ${ }^{68}$. Y si ya existía eso desde el surrealismo verdadero (el de los automatistas, el de Miró, no el de los super-representativistas) son los aformalistas los que nos proporcionaron la sensibilidad necesaria para captar ese descubrimiento.

Continuando con el análisis de la pervivencia de la tradición en la vanguardia, la segunda, la que empezó en 1956 con Tàpies, Moreno Galván dice: «De manera que ese aire de familia que podemos encontrar, por ejemplo, en la pintura de Antonio Saura y en los más violentos lienzos de Goya, no se ha conseguido por una consciente búsqueda genealógica del primero en el segundo, sino por la supervivencia de una realidad que continúa siendo la misma en Goya y en Saura" ${ }^{69}$. Lejos de conceder a El Paso, y al arte español del momento una ilación con la tradición española más allá de ese aire de familia, cree que el expresionsimo violento nada tiene que ver con la «veta brava» sino antes con EE.UU., Francia y Alemania. Finalmente, Moreno Galván fija dos orígenes distintos para el aformalismo: uno es el surrealismo y otro el expresionismo y si el segundo deriva del primero, no tiene por qué ser punto de paso obligado para llegar al aformalismo.

L. Toussaint, con su libro sobre El Paso, primera monografía de largo alcance, accesible e integradora, se convierte en referente justo y obliga-

Bozal:: Arte español del siglo XX. Op.cit., pág. 259.

Ibídem, pág. 116.

Autocrítica de arte. Península, Madrid, 1965. Capítulo I.

6 La última vanguardia. Magius, Madrid, 1969. pág. 11. 
do de todo estudio. Para él la figura clave es Saura, seguido por un celoso Millares. Feito y Canogar formarían como otro Paso, oscuro, al margen del de estos dos faros ${ }^{70}$. Su estudio va dirigido más al papel del grupo como tal que a la obra de cada uno de sus integrantes analizando su papel sociológico-artístico. Tras una preparación de la catarsis a las que nos va a conducir El Paso ${ }^{71}$, se tiende a presentarle como protagonista de todos los cambios habidos en el momento, sin que eso desmerezca las obras de otros artistas ni la participación de los personajes oficiales. Puede considerársele el forjador del mito, tanto más desde el momento en que la historiografía española ha demostrado su debilidad por los estudios foráneos sobre lo ibérico ${ }^{72}$.

Su disolución se debería al éxito personal y no tanto a la respuesta a la insistida "paradoja» de su postura ante el Régimen. Pero, por encima de todo, El Paso marcó «una era nueva, pese a que el entusiasmo general de la crítica [fuera] pasajero» ${ }^{73}$.

Calvo Serraller es el que en mayor medida defiende la importancia de El Paso como punto de inflexión, en ciertos aspectos al menos, del arte español. Gracias al triunfo del informalismo -al que El Paso haría las principales aportaciones por lo menos propagandísticas- pudo pensarse que no era obligatorio el exilio para continuar creando desde una senda ideológica, incluyendo también a lo estético.

Del mismo modo es el autor que ha establecido otra línea de interpretación de las "claudicaciones" y "oportunismos" - que los hubo- de los miembros de El Paso a la hora de blanquear la imagen del Régimen. Según

7o La misma opinión se repite en el caso de J.M. BONET que habla de una vertiente lírica como criterio de división y que integrarian Rivera, Suárez y Feito. "Volviendo sobre El Paso», en cat.exp. El Paso después de El Paso, enero 1988, Fundación Juan March, s.p. y también Ángel CRESPo que dividió el grupo en críticos (Saura y Millares) y esteticistas (Canogar, Rivera y Feito) en «Un ejemplo: El Paso», en Artes, extra, dic 64, pág. 23.

71 El estudio se abre con una afirmación más literaria que real para esos años: «En la historia internacional del arte contemporáneo, España todavía es ignorada, pese a que los artistas modernos de más renombre se llamen P. Picasso, J. Gris, J. Miró, S. Dalí».

${ }_{72}$ Discusión ésta que reparte rápidamente sus papeles de xenófobos sutiles y adoradores reverentes de cuanto lleve un marchamo no español. Tal vez sea por eso que la realidad inversa sea difícil de encontrar. Aplicable a la historia del arte es lo que se dice de la historia contemporánea: «Entre nosotros no hay quien haga historia de Francia, de Gran Bretaña, de Rusia o de Estados Unidos (...) es imposible establecer una relación de reciprocidad con nuestros colegas extranjeros». José ÁLVAREZ Juncos y Santos JULIÁ, «Tendencias actuales y perspectivas de investigación en Historia Contemporánea», en Tendencias en Historia, Madrid, CSIC,1988. pág. 56. Aunque al respecto Fernand Braudel dijera: «|'historien n'est de plain-pied qu'avec l'histoire de son propre pays".

73 ToussainT: op.cit., págs. 142 y 144. 
su interpretación, crítica con la de Gabriel Ureña, sería el Régimen y no el grupo el que sufriría el escarnio de su doble moral, entendiéndose implícitamente que en el exterior se conocía lo que dentro de España ocurría. Aunque poco verosímil, no se excluye que fuera así: que faltando tales libertades y/o formas de desarrollo en toda la sociedad, era lógico inferir que estuviera ocurriendo lo que de hecho ocurría (no es seguro que un Blanco White redivivo estuviera completamente de acuerdo). Llega a apuntar que la extinción del grupo tuvo que ver también con la crisis del informalismo en todo el horizonte artístico internacional. El pop se anunciaba y Bacon pintaba.

Todo ello hace que destaque al grupo El Paso en el contexto del momento despegándolo del plano formado por otros como Equipo 57 y Parpalló. De la misma manera, resta importancia categóricamente al papel jugado desde las instituciones: podría haber todos los comisarios «avisados" que se quisiera pero no pintaban cuadros ${ }^{74}$. Eso no significa que haga de El Paso el estandarte de la rabiosa vanguardia que salva al país de su males artísticos: previamente ha establecido una línea desde la $A B C A$, continuada por mor de sus integrantes en la Escuela de Altamira, hasta la I Bienal Hispano-Americana con los mismos, coincidiendo en esto con Cabañas y Moreno Galván.

En cuanto a la conjugación de tradición y modernidad que realizaría El Paso, sí habla de dramatismo, de esa imagen nacida en el romanticismo y que estudió en La imagen romántica de España. Tras situar el inicio de ese interés por las invariantes del arte español dentro de los grupos contemporáneos en la Escuela de Vallecas, retrotrae ese interés hasta la generación del 98, como Bozal y Llorens ${ }^{75}$.

Valeriano Bozal desmitifica la importancia de El Paso en el contexto del año 57 frente al interés destacado de sus dos protagonistas principales: Saura y Millares. También frente a los cambios políticos y sociológicos globales del momento (en el 57 terminaría la postguerra, ¿o la guerra? se pregunta), puesto que algunos artistas ya tenían una proyección antes de la intervención oficial, como Tàpies. Pero no adelanta la fecha de inflexión a los años previos al 57: «1951 a 1953 y 1954 son años decisivos para esa madurez, pero no son todavía años de «movimiento» colectivo» ${ }^{76}$. En cual-

\footnotetext{
${ }^{74}$ F. Calvo Serraller: Del futuro al pasado. Vanguardia y tradición en el arte español contemporáneo. Madrid, 1988. p. 112.

75 Vid. nota 8. La recurrencia al 98 también ha sido puesta de manifiesto por J.M. Bonet así como atacada por García Felguera. Canogar llegó a citar a D'Ors sobre la tradición en CIRLOT: De la crítica..., op.cit.

${ }_{76}$ Arte del siglo XX en España: pintura y escultura. Vol II (1939-1990). Espasa, Madrid, 1991. pág. 265.
} 
quier caso, la trama sobre la que apoya el análisis es mucho más prolija, relacionando la génesis del informalismo con el pensamiento existencialista, causa y efecto del individualismo moderno que, a su vez, sería el punto de partida del informalismo, palabra cargada de connotaciones contrapuestas, cajón de sastre de obras tan dispares que denomina «galaxia informalista». Tapié, su teórico de más peso, partiría así del análisis de Heidegger para elucidar su art autre - aunque él diga que su base es Dubuffet a quien se le relaciona con el filósofo, pero relación que no aceptaba ${ }^{77}$ - Todo ello no obsta para que Bozal considere que «El Paso se convirtió de inmediato en la máxima expresión del nuevo arte español. Es posible que en este proceso hubiera un componente de manipulación por parte de las instituciones, pero no tengo duda de que, como grupo, era efectivamente la máxima expresión del arte español de vanguardia». Y los sustantivos que colecta y definen a El Paso según los críticos serían: «Vigor, expresión, sobriedad, austeridad, misticismo, elementalidad, potencia, naturaleza, etc.», o, de propia cosecha: «marcado acento español: dramatismo, cromatismo, énfasis realista, expresividad a ultranza, etc. ${ }^{78}$.

Aunque no lo haga con el grupo entero sino sólo con alguno de sus componentes (Saura en concreto) es de los pocos autores que señala la relación e influencia de Alberto Greco sobre El Paso ${ }^{79}$. Saura y él aportarían los ingredientes surrealistas (automáticos -y casi dadá en el caso de Greco-) ${ }^{80}$.

josé Manuel Bonet destaca no sólo por el rosario de artículos en los que ha demostrado su erudición sino también por representar el punto de vista opuesto al que ocupa en la crítica Bozal ${ }^{81}$. Como en el caso de

77 «Pregunta: Quiero decir que en esos temas (...) me parece descubrirse una visión trágica de lo irrisorio humano que quizás tuviera una correspondecia con la filosofía de Heidegger. Respuesta: Dejemos a Heidegger en paz, pues no me gusta la filosofía, a no ser que sea implícita». Entrevista de Choay a Dubuffet, en J. DubufFeT: op. cit., pág. 272.

78 V. BozaL: Arte del siglo XX en España..., op. cit, págs. 271 y 273.

79 A esa relación ya aludió J.M. BONET en su texto «Volviendo sobre El Paso», op.cit., donde también menciona la relación de los canarios del grupo (Millares y Chirino) con ZAJ. Quien más claramente refiere la relación con Greco es E. GonzÁLEZ NAVARRo en Diccionario de pintores y escultores españoles del siglo XX. Forum Artis, Madrid, s.f. Bajo la entrada "Greco, Alberto" pone: «Su obra ejerció una gran influencia sobre el grupo El Paso (...) En la muestra colectiva de homenaje a M. Millares, celebrada en Juana Mordó en 1973, figuraron algunas de sus obras". Para ese momento Greco ya se había suicidado.

80 Saura organizó la exposición Arte fantástico antes de la creación de El Paso. No arte surrealista, como hace notar Moreno Galván que presenta a un Saura receloso del carácter nostálgico de los surrealistas de los años 50, y que intentaría echar cortinas de humo sobre su relación con ellos. Vid. MOREno GaLVÁN: La última vanguardia, op.cit. Pese a que luego reconociera cierta nostalgia por el movimiento. Vid. CIRLoT: De la crítica de arte..., op. cit.

81 Enfrentamiento que abiertamente sostuvo en «Después de la batalla», en Cat. exp. 1980, Juana Mordó, Madrid, octubre de 1979. En ese combativo texto, anteriormente publicado en el 
Areán es su condición de crítico la que le hace alejarse de teorías y jerarquizaciones y referirse antes a los pintores como tales que a los sistemas que paralelamente puedan establecer: «El Paso nace en Madrid como agrupación de individualidades, y con el propósito de articular una alternativa expresionista abstracta» ${ }^{82}$.

Su opinión no tiene paliativos: "Que El Paso catalizó las cosas y no sólo en Madrid, nadie lo duda" ${ }^{83}$. Sus claves están claras: expresionismo abstracto en directa conexión con el norteamericano, voluntad normalizadora en todo lo que rodea a la producción artística, raíz en lo español. Pero esta raíz, lo más comentado, no vendría sino una vez desaparecido el grupo.

Defiende su valentía. Ante las arpilleras «percibiremos el valor que Millares y sus compañeros de El Paso tenían cuando se planteaban su trabajo en esa línea». Y Saura tendría la misma condición de rara avis entonces por buscar los "grandes temas": sexo, muerte, religión, violencia, tratados desde «estructuras matrices» con interés por la action painting pero sin desprenderse del apoyo en los motivos figurativos y que le sirven para revisar libremente el pasado (las tres gracias, Goya, Dora Maar). El proceso es complejo: según Saura se trata de encontrar «una imagen deseada a través de signos que la posibilitan», interesándose por el «espectro de la misma y sus resonancias afectivas» ${ }^{84}$. De EEUU, representados por Pollock, toma la gran superficie que le permite liberar el gesto rápido pero sin «sumirse en una actividad pictórica sin control». Su otro pilar es la tradición española de gama oscura. Toma motivos de El Greco, Valdés Leal, el Ribera de la Mujer Barbuda, Gutiérrez Solana y especialmente del Goya de las Pinturas Negras. Bonet destaca de Saura su fuerza expresiva a la vez que su contención, lo que le inscribe en la línea de la mejor pintura española. $Y$, sobre todo, su humor negro que aprende de los surrealistas y que le hermana con CoBrA a través de sus Cocktail parties. De Feito, además de sus «paisajes» y los colores «tan nuestros» organizados siempre en torno a un núcleo, dice: «El

suplemento Sábado literario del diario Pueblo, decía: «Entre tanto Bozal y tanto Rubert, entre tanto Tomás Llorens y tanta traducción de Umberto Eco, entre tanto pop y tanto op y tanto medio y tanto mensaje, casi consiguen hacernos olvidar la verdad de la pintura, la necesidad y la pasión y el placer de la pintura", y más adelante "Aun a sabiendas de lo poco de acuerdo que estábamos con un Bozal o con un Marchán, la muleta marxista seguía tentando...», y luego alude a "Bozal y sus amigos" como poco atinados en sus decisiones en la interpretación politizada presentada en la Bienal del 76.

${ }_{82}$ La cita y siguientes figuran en los distintos catálogos que para la Fundación Juan March realizó J.M.BONET. En la presente, el subrayado es nuestro.

${ }_{83}$ "Volviendo sobre El Paso", op.cit.

${ }^{84}$ Saura: «Para realizar un retrato, la presencia del modelo cuenta menos que el fantasma mental por él forjado". 
cuadro es para Feito, más que para cualquier otro pintor de la generación, una realidad autónoma, regida por sus propias leyes. En eso enlaza con los pioneros de la abstracción". Para Conde era en cambio Canogar el más «formalista» de todos ellos, en el sentido de que le interesan sobre todo los problemas intra-pictóricos, la «expresión directa de la obra en sí» ${ }^{85}$. Bonet le retrata como un cromatista exaltado que reduce después su paleta basándose siempre en la tradición española, en la del Greco, algo que ya destacó la crítica del momento. Viola también siguió el camino del surrealismo a la abstracción (desde los Logicofobistes). En el 58, cuando entra en El Paso, ya era "el más vehemente de nuestros expresionistas abstractos». Pintor culto, el más místico del grupo, es la relación más fuerte con ese pasado que convive con la Contrarreforma. Serrano, experimentado como Viola antes de entrar en El Paso, diferiría de él por "conectar más con su generación por lo figurativo que por lo abstracto". De Rivera se destaca el uso de un material pobre, inusual, y «ha de ser considerado como uno de los artistas más característicos de los cincuenta», como por recoger la historia y la tradición.

Bonet es, junto con Calvo Serraller, el que más ha incidido en la importancia del carácter didáctico del Museo de Arte Abstracto de Cuenca, única institución destacable en un panorama paupérrimo durante años.

\section{A MODO DE CONCLUSIÓN}

Se ha intentado aquí recopilar la principal bibliografía sobre el grupo y analizar las líneas de estudio según la crítica para desarrollar el marco que las defina verosímilmente. Éstas, apuntadas al principio, aunque se discuta su intensidad, aparecen inmisericordemente en los estudios incluso como títulos de alguno de ellos. El contexto de su desarrollo puede ser tan rico como el que apuntan Bozal o Calvo Serraller o tan reducido a personalidades como lo quieran otros, sea a las de los propios artistas o a las de González Robles y Fernández del Amo. Pero puede entenderse que son iniciadores de una forma de crear dentro de España, inusual hasta entonces ${ }^{86} y$ que definirá una actitud ante la pintura que va a ser seguida durante un tiempo, justo hasta cuando el informalismo sea ya a las claras

as «El lenguaje de la crítica de arte y su eficacia», loc. cit.

86 «Probablemente, esa corriente de emigración artística hubiera continuado creciendo sin interrupción si el triunfo internacional del informalismo español no hubiera cambiado algo en España la actitud oficial y social frente al arte de vanguardia. A partir de entonces, aunque sólo afectara verdaderamente a una minoría, comenzó a resultar verosímil la posibilidad de sobrevivir en España sin claudicar de los principios renovadores». Francisco Calvo SerRaller: España. Medio sig. 0 de arte de vanguardia, op.cit., p.68. 
una forma de no arriesgar nada ganándolo todo, sinónimo, quién lo iba a decir, de comodidad y en última instancia garantía de buena colocación en el mercado. Si bien el «formato» de grupo no tendrá continuadores más que excepcionalmente como reflejaba Saura casi con lamento hace poco y que él intentó remediar con su adscripción a Estampa Popular. Lamento que también se extendía a una falta de cierta ética ante la pintura y el arte todo, especialmente visible, según él, desde la Nueva Generación de Aguirre, pese a que reconozca la calidad de las obras de algunos de ellos. Aguirre, que fue a mediados de los sesenta el crítico más implacable de El Paso por su dramatismo, su obsesión españolista y su reduccionismo cromático ${ }^{87}$.

Pero EI Paso sí buscaba un contenido para sus obras dentro de ese debate sobre el contenido en el informalismo y en el arte que algunos años después daría lugar a uno sin él, voluntariamente vacío. Quería uno para la suya aunque no tuviera claro cuál: para Conde era el espacio y el tiempo, para Saura la angustia, para Millares no sabía qué. Pero a las claras debía ser beligerante. Ya fuera en la estética, en la factura o en el tema. $Y$ lo demostraban con sus series y variaciones sobre intocables como pudieran serlo los curas, los de Saura o los de Millares. Con ello además demostraron que el artista no siempre pinta de cara a la galería. En esas obras y en las otras se debatía algo más que la estética, la factura o el tema. Se debatía sobre la esencia del arte español ${ }^{88}$.

Desde que a inicios del verano del 57 se empieza a hablar por doquier de El Paso, algo cambió en el arte y en la sociedad española. Pero todo cénit tiene su nadir, y así la favorable acogida de la crítica internacional, que ya hemos visto como merodeó por España durante un tiempo, terminó por abandonarse al movimiento sacádico y cambió de sitio la mirada, devolviéndonos a unos «años de penitencia y meditación» en los setenta, en los que la exhibición sistemática de la vanguardia no demostró haberse consolidado ${ }^{89}$.

Aún se habla de ello, aun faltando la consabida efemérides que dé pie a ella ${ }^{90}$, y El Paso se convierte todavía en un referente historiográfico.

${ }^{87}$ J.M. BONET: El Paso después de El paso, op.cit., s.p.

88 BOZAL y LLORENS decían en su España: vanguardia artística y realidad social que El Paso debe ser entendido en su contexto de revisión de los problemas de España, a saber; a) El problema de España en sí que empezó a ser objeto de atención a principio de los 50 como resultado de una revisión y una reinterpretación polémica de la Generación del 98 y b) el problema filosófico de las raíces éticas de la libertad individual (para lo que también hay que acudir a la Generación del 98, sobre todo a Unamuno, pero también a los existencialistas). $Y$ todo ello desde el contexto de la dictadura.

89 Calvo Serraller: España. Medio siglo de arte de vanguardia, op.cit., pp. 89, 94 y ss.

90 Las casas de subastas la encontraron: El Paso: revisión del grupo El Paso en su 40 aniversario, Finarte, Madrid, abril 1997. Como también René Metrás en el XVII aniversario de su fundación y luego Multitud. 
